\title{
High-Temperature Performance of Actively Cooled Vapor Phase Strengthened Nickel-Based Thermostructural Panels
}

\author{
Sara J. Pérez-Bergquist* \\ University of Michigan, Ann Arbor, Michigan 48109 \\ and \\ Natasha Vermaak and Tresa M. Pollock \\ University of California, Santa Barbara, Santa Barbara, California 93106
}

DOI: $\underline{10.2514 / 1 . J 050815}$

\begin{abstract}
Actively cooled thermostructural panels for use in emerging hypersonic flight systems require advanced materials able to support substantial loads at elevated temperatures. Identifying formable structural materials with strength, toughness, and oxidation resistance is a major challenge in this advancing technology. Geometrical optimization of thermostructural panels for scramjet applications minimizing mass with appropriate mechanical strength and cooling capacity combinations often requires submillimeter wall and face-sheet thicknesses. A new processing method was developed, resulting in rectangular-channeled panels made of nickel-based precipitation-strengthened alloy in a previously unobtainable thin-walled geometry suitable for active cooling. The processing method begins with panel fabrication from submillimeter-thin sheets of a Ni-based solid-solution alloy. The strength of the panel is subsequently increased by vapor phase aluminization combined with an annealing treatment. The vapor phase strengthening process increases the yield strength of the panel by a factor of approximately three. Panels were fabricated with geometry representative of optimal designs and tested at high temperature with active cooling in both as-fabricated and strengthened states. The strengthened, actively cooled panel withstood a temperature $478^{\circ} \mathrm{C}$ higher than the as-fabricated panel before failure under high heat flux conditions, indicating that the vapor phase strengthening process provides substantial new performance capabilities.
\end{abstract}

\section{Introduction}

$\mathbf{T}$ HERE is a need for strong, lightweight, high-temperature, and oxidation-resistant structures in advanced high-Mach-number aerospace flight systems: in particular, hypersonic vehicles. Where possible, metallic panels are desirable due to their high resistance to damage and the availability of relatively low-cost manufacturing approaches. Examples of possible areas where metallic structures would be especially useful include inlet panels and combustion chamber liners for scramjet engines and non-leading-edge acreage panels that must endure extremely demanding high-temperature (near $1000^{\circ} \mathrm{C}$ ) and oxidation conditions when operating at Mach 7 cruise conditions [1-4]. Thermostructural panels with prismatic cores, honeycomb, or Kagomé structures [5] show great promise to fulfill these structural requirements (examples shown in Fig. 1). To address the structural and heat flux requirements, the geometry of thermostructural panels can be optimized for a combination of mechanical strength and cooling capacity [6]. Thus, fabrication approaches for a wide range of panel geometries are needed.

Nickel-based superalloys with high volume fractions of $\gamma^{\prime}\left(\mathrm{Ni}_{3} \mathrm{Al}\right)$ precipitates are often used in high-temperature aerospace applications, and many of these alloys can be conventionally cast into near-net shape forms; however, the submillimeter-thin walls often required for structural optimization of thermostructural panels pose major challenges for conventional investment casting of nickelbased alloys [4]. While fabrication from thin-gauge sheet materials is an efficient alternative approach, most nickel-based alloys available in sheet form have severely limited high-temperature creep properties. Conversely, many refractory-lean $\gamma$-nickel alloys (without precipitation strengthening) are readily processed into thin sheets

Received 5 October 2010; revision received 13 December 2010; accepted for publication 14 December 2010. Copyright (C) 2011 by the American Institute of Aeronautics and Astronautics, Inc. All rights reserved. Copies of this paper may be made for personal or internal use, on condition that the copier pay the $\$ 10.00$ per-copy fee to the Copyright Clearance Center, Inc. 222 Rosewood Drive, Danvers, MA 01923; include the code 0001-1452/11 and $\$ 10.00$ in correspondence with the CCC.

*Currently Los Alamos National Laboratory, Los Alamos, New Mexico 87544. and shaped at room temperature. Although it is possible to fabricate panels with the required geometries from thin wrought sheets of these alloys, to be used as a thermostructural panel, the hightemperature mechanical properties of these alloys must be improved. An increase in strength and maximum use temperature will allow for an actively cooled thermostructural panel to be very attractive when optimizing designs that combine structural load capacity with heat dissipation $[2,7,8]$. Precipitation strengthening is the most efficient strengthening approach, but it must not interfere with the sheet processing operations.

To achieve a more optimal combination of high-temperature strength and thin-walled geometrical structure essential for a scramjet engine application, a processing method that consists of deposition of an aluminide layer with subsequent annealing to drive the aluminum through the sheet thickness has been developed. This process results in precipitation strengthening of the alloy in a postfabricated state resulting in a panel geometry that was previously unattainable. It is possible to produce the aluminide layer via pack cementation [ [ -10$]$ and, with the resulting concentration gradient of aluminum, annealing will result in the homogenization of the aluminum through the thickness of the sheet $[11,12]$. The feasibility of this strengthening approach is reported elsewhere for a variety of wrought alloys [13] as well as for a prismatic-core thermostructural panel [14].

Vermaak et al. has developed an optimization code for rectangularchanneled panels to be used in the combustor of a scramjet engine [15] that yields lightweight designs subject to constraints relating to stresses, temperatures, and manufacturability. The code takes material properties and hypersonic vehicle parameters as inputs and determines the optimum cooling channel geometry for a range of coolant flow and combustion heat transfer conditions. The full list of material properties used include density, coefficient of thermal expansion, Young's modulus, conductivity, Poisson's ratio, maximum use temperature, reference yield strength (yield strength at $127^{\circ} \mathrm{C}$ ), and the degradation of yield strength with temperature. Table 1 includes the values for the material properties that were held constant for the optimizations in this study. The merit of the combustor optimization code is that it facilitates communication between design variables and material properties. The weight 


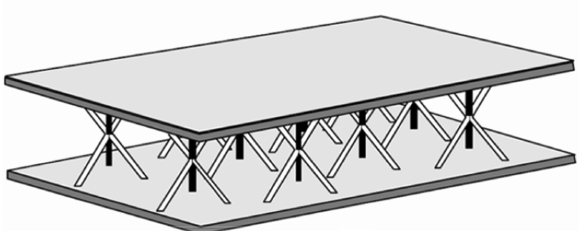

a)

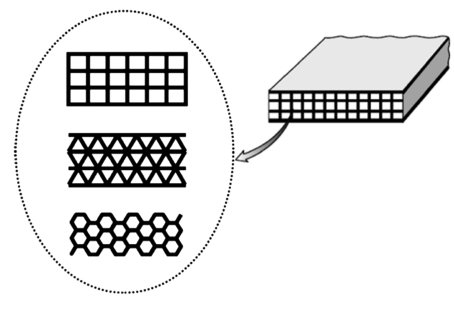

b)

Fig. 1 Examples of configurations for thermostructural panels: a) Kagomé []] and b) prismatic cores [2]].

performance of candidate materials considered by Vermaak et al. is shown in Fig. 2 for two support conditions representing a range of designs. The main difference between the support conditions is that, for design II, the combustor liner is fully supported by a stiff sandwich structure. This eliminates panel-level bending induced by the combustion pressure between the periodic supports of design I. Optimized panel weights are plotted for both designs as a function of the equivalence ratio. The equivalence ratio $\phi$ is a nondimensional measure of the coolant flow. The coolant (fuel) is allowed to flow through the cooling channels at (or near) the stoichiometric flow rate. This rate is the fuel/air ratio necessary for complete mutual combustion. While stoichiometric $(\phi=1)$ or lean fuel flow rates $(\phi<1)$ are preferred, richer mixtures $(\phi>1)$ are often necessary to compensate for combustion inefficiencies. In Fig. 2, it is clear that a panel fabricated from $\mathrm{C}$-SiC yields the lightest panel over the entire range of equivalence ratio.

In order for metallic systems to compete with a $\mathrm{C}$-SiC panel, the material properties must be improved. However, due to the complex relationships between material properties and the optimized geometry, the role of specific material properties is not easily assessed. Vermaak et al. [15] considered the effects of increasing two parameters on the optimized weight of a panel: the reference yield strength $S^{*}$ and the maximum use temperature $T^{*}$, above which the mechanical properties drop off precipitously. Although this investigation gave some insight into the relative importance of which material properties to improve, the integration of this code with a strengthening model is necessary to determine a goal microstructure that produces a panel with the global minimum weight. Kozar et al. [16] has developed a yield strength model for nickel-based superalloys. This model predicts the strengthening that can be achieved based on microstructrual features, including size and volume fraction of multiple populations of $\mathrm{Ni}_{3} \mathrm{Al}\left(\gamma^{\prime}\right)$ precipitates. By integrating a panel geometry optimization code and a microstructural strengthening model, a thermomechanically loaded panel can be optimized for minimum weight using both structural and microstructural controls.

The superior performance of the vapor phase strengthened (VPS) X-750 material predicted by the optimization code is shown in Figs. $3 \mathrm{a}$ and $3 \mathrm{~b}$. The areas of feasibility for both the as-received X-750 and the VPS X-750 are presented in terms of the thermal load and coolant flow in Fig. 3a. The thermal load parameter $\chi$ represents the amplification of the combustion heat transfer coefficient relative to the expected steady-state value for Mach 7 flight [17]. The strengthened material improves performance by allowing operation to lower coolant flow and higher thermal loading. The corresponding weight performance for the as-received and strengthened materials is compared with the benchmark ceramic matrix composite (CMC) $\mathrm{C}-\mathrm{SiC}$ solution, in Fig. $3 \mathrm{~b}$, for a fixed level of thermal load (the

Table 1 Values of material properties considered constant in the panel geometry code for this application

\begin{tabular}{lc}
\hline \hline Property & Value \\
\hline Density & $8276 \mathrm{~kg} / \mathrm{m}^{3}$ \\
Coefficient of thermal expansion & $16.0 \times 10^{-6} 1 / \mathrm{K}$ \\
Young's modulus & $128 \times 10^{9} \mathrm{~Pa}$ \\
Conductivity & $23.0 \mathrm{~W} / \mathrm{mK}$ \\
Poisson's ratio & 0.30 \\
\hline \hline
\end{tabular}

steady-state value of combustion heat transfer coefficient for Mach 7 flight, $\chi=1$, is assumed). The strengthened $X-750$ allows significant weight reductions (Fig. 3b). Although the benefit is less pronounced for design II, the same trend is exhibited. Note also that the strength model for Inconel X-750 originally assumed by Vermaak et al. [15] is aggressive; thus, some of the actual benefit of the VPS X-750 material is masked. Nevertheless, VPS is shown to be a viable approach applicable to a range of designs.

Using the models described previously, a combination of material and panel geometry representative of optimal results under design II support conditions has been identified for performance testing. The panel consists of face-sheet and web thicknesses of $0.4 \mathrm{~mm}$ and channel dimensions of $5 \times 8.5 \mathrm{~mm}$. The jointly optimized microstructure consisted of a total of $40 \mathrm{vol} \% \gamma^{\prime}$ precipitates with two precipitate populations ( $20 \%$ at $110 \mathrm{~nm}$ and $20 \%$ at $25 \mathrm{~nm}$ ). Using thermodynamic modeling and tensile samples, panels with the optimal geometry and microstructure were fabricated and strengthened with the preceding approach. Room temperature tensile tests were completed, and the high-temperature performance of these panels was tested by aggressively heating the panel on one side while actively cooling the panels with water. The improvement in performance of the strengthened panels is discussed in detail.

\section{Procedure}

As mentioned previously, the panel geometry determined from the integrated modeling consisted of face-sheet and channel webbing thicknesses of $0.4 \mathrm{~mm}$ using X-750 (composition in Table 2 [18]) as the starting base alloy. To achieve the very thin walls typical for optimized panels, the channels were electric discharge machined (EDM) from a thick plate of material. Four panels were created by starting with plate stock and traditionally machined to size with a three-axis mill of $5.8 \times 45 \times 63.5 \mathrm{~mm}$. The channels were created by drilling holes for the channels and cutting out the material with a wire EDM to create five channels with dimensions of $5 \times 8.5 \mathrm{~mm}$, leaving a wall thickness of $0.4 \mathrm{~mm}$. It is worth noting that other processing routes, such as brazing thin wall sheets, may be a more suitable processing approach; however, thin sheets were not available in small quantities.

Tensile tests were performed to characterize the change in roomtemperature yield strength for the optimized alloy microstructure. Samples were cut with an EDM process. The dimensions of the samples were $10 \times 65 \times 0.65 \mathrm{~mm}$ with a gauge section length of $25 \mathrm{~mm}$. The radius of curvature from the grips down to the gauge section thickness was $5 \mathrm{~mm}$.

After fabrication, the panels and tensile samples were subsequently aluminized via pack cementation using a high-activity pack with its aluminum source greater than $60 \mathrm{wt} \% \mathrm{Al}$ [9], using the process described by Das et al. [19]. The pack cementation is a chemical vapor deposition process that does not require line of sight to ensure that all surfaces are uniformly coated [20]. The pack and panel were contained in a stainless steel container. The pack contained 82 wt \% $\alpha$-Al203 (99.9\%), 15 wt \% Al powder $(-40+325$ mesh, $99.8 \%)$, and 3 wt $\% \mathrm{NH} 4 \mathrm{Cl}$ (99.5\% $\mathrm{min})$. The container was inserted into a cold zone of the vertical tube furnace with flowing Ar. The container was moved to the hot zone and held for $3 \mathrm{~h}$ at $850^{\circ} \mathrm{C}$, then it was moved to a cold zone of the furnace until cool enough to handle. Following aluminization, the samples were 


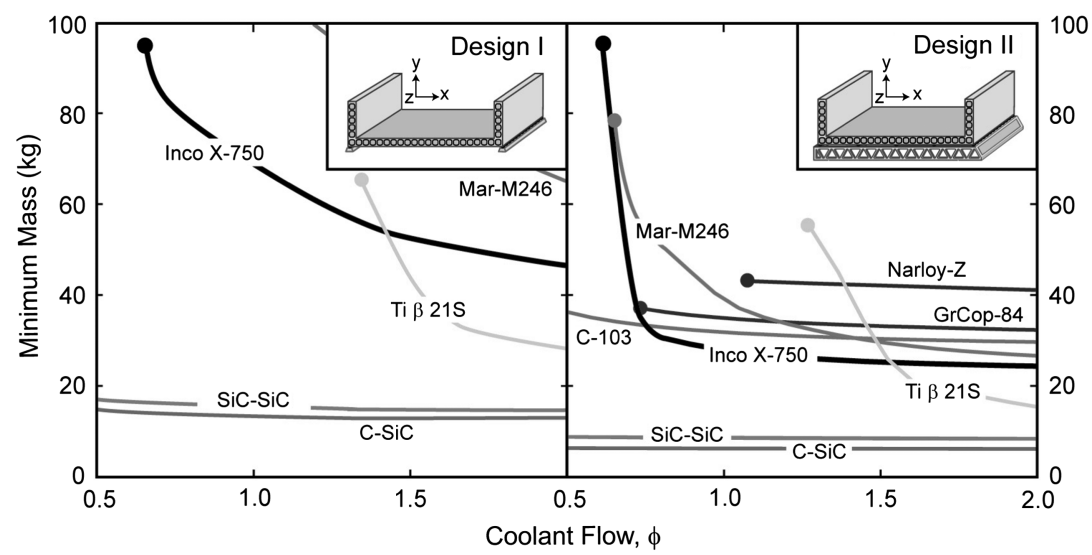

Fig. 2 Thermostructural combustor liners geometrically optimized for minimum mass.

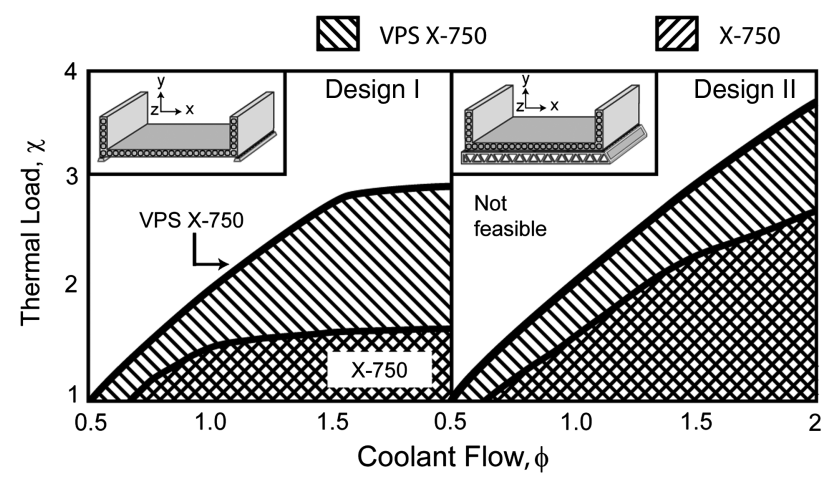

a)

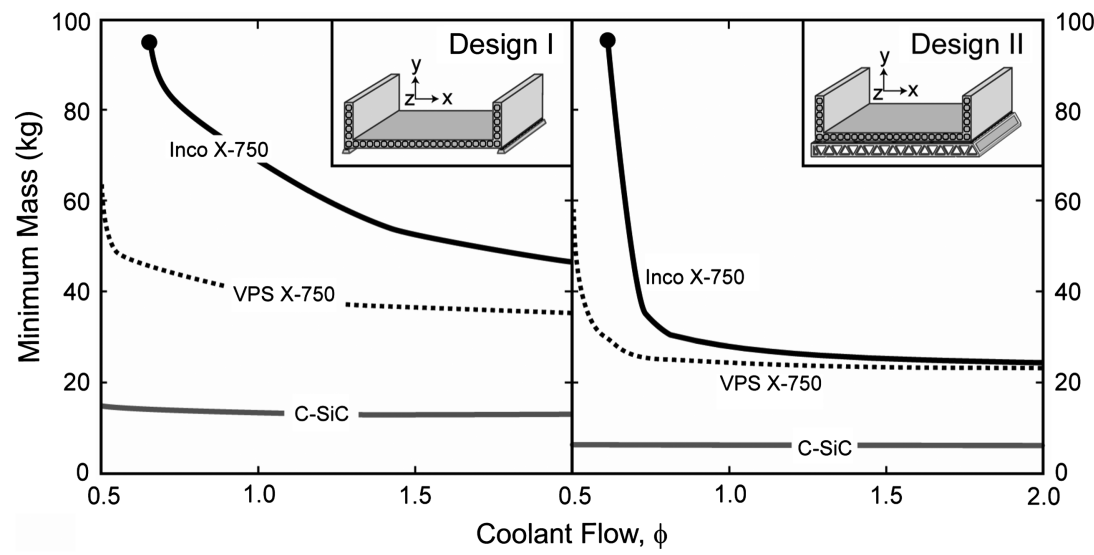

b)

Fig. 3 Optimization results including the VPS X-750 material: a) feasible solution space and b) relative weight savings.

ultrasonically cleaned in water. The cleaned panels and tensile samples were placed in a vertical tube furnace with flowing $\mathrm{Ar}+$ $3 \% \mathrm{H}_{2}$ and annealed for $200 \mathrm{~h}$ at $1100^{\circ} \mathrm{C}$ to homogenize the $\mathrm{Al}$ concentration through the thickness of the tensile samples and panel walls. This annealing treatment was determined with a Fourier series approximation to achieve Al homogenization within \pm 10 at. $\%$. Further details of this VPS approach applied to a wider set of starting materials is discussed in detail elsewhere [13].

To achieve the desired microstructure, solution and aging temperatures were determined for the altered X-750 alloy with Pandat $^{\mathrm{TM}}$ thermodynamic software. Solution treatments were carried out at $1200^{\circ} \mathrm{C}$, while the pair of aging temperatures were 1075 and $980^{\circ} \mathrm{C}$. As mentioned previously, the goal microstructure consisted of a total $40 \mathrm{vol} \% \gamma^{\prime}$ (half at $110 \mathrm{~nm}$ and half at $25 \mathrm{~nm}$ ). Ostwald ripening was used to determine approximate aging times to achieve precipitate populations with sizes of 110 and $25 \mathrm{~nm}$ of $16 \mathrm{~min}$ at $1075^{\circ} \mathrm{C}$ and $2 \mathrm{~min}$ at $980^{\circ} \mathrm{C}$, respectively. An environmentally controlled vertical tube furnace with the ability to quickly move the sample from the hot zone to the cool zone was used to achieve these very short aging treatments. The cool zone of the furnace remained at

Table 2 Composition of alloy X-750 [18]

\begin{tabular}{cc}
\hline \hline Alloy & H-X750 \\
\hline $\mathrm{Ni}$ & Bal. \\
$\mathrm{Cr}$ & 16 \\
$\mathrm{Al}$ & 0.8 \\
$\mathrm{Fe}$ & 8 \\
$\mathrm{Ti}$ & 1 \\
$\mathrm{Nb}$ & 1 \\
$\mathrm{Co}$ & 2.5 \\
\hline \hline
\end{tabular}




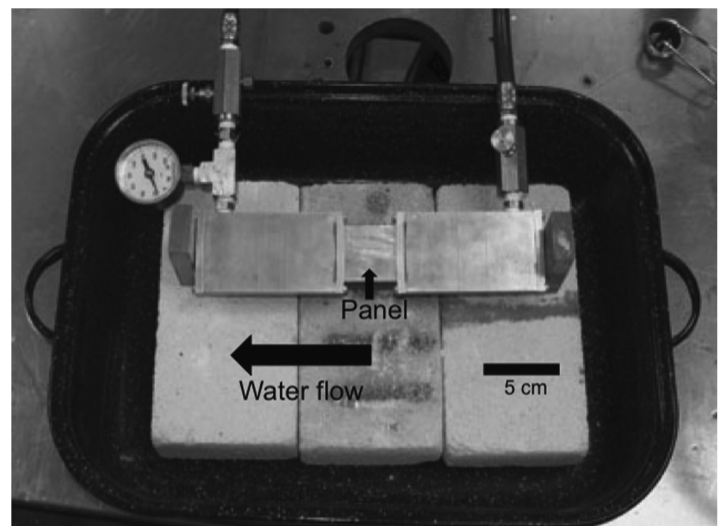

Fig. 4 Image of the high-temperature testing apparatus for the actively cooled thermostructural panel.

temperatures no greater than $250^{\circ} \mathrm{C}$ throughout the treatments, and cooling rates were approximately $50^{\circ} \mathrm{C} / \mathrm{s}$. The solution treatment was $1 \mathrm{~h}$ at $1200^{\circ} \mathrm{C}$ for all tensile samples and panels. Because of the approximate nature of the kinetic constant $k$, aging treatments for the tensile samples were carried out for a range of times: 13 to $19 \mathrm{~min}$ at $1075^{\circ} \mathrm{C}$ and 2 to $5 \mathrm{~min}$ at $980^{\circ} \mathrm{C}$. The two-step aging treatment produces a bimodal precipitate distribution, which is predicted to provide greater strengthening than a heat treatment at a single temperature. The aging treatment for the panels was determined from the results of the tensile tests.

The tensile samples were tested in tension with an Instron 5582 with a constant displacement of $0.05 \mathrm{~mm} / \mathrm{min}$. The strain was measured with an Instron edge grip extensometer with a 12.7-mmgauge length. Measurements of Young's modulus, yield strength, and ultimate tensile strength were performed for all of the samples.

The testing apparatus (Fig. 4) for the panels was designed to allow the panels to be heated on one side with an oxyacetylene torch while being actively cooled by water flowing through the channels at a variety of pressures to determine the performance of the panels at high temperature. The water traveled through a brass fixture designed to produce turbulent flow through the panel. The water pressure inside all of the cooling channels was kept constant at $0.4 \mathrm{MPa}$, with a flow rate of $16 \mathrm{~cm}^{3} / \mathrm{s}$ to achieve a surface temperature sufficiently high to induce failure of the panels. Both the as-fabricated and strengthened panels were subjected to similar torch conditions, keeping the flow rate of both oxygen and acetylene constant during testing. The torch was held at a distance approximately $10 \mathrm{~mm}$ from the sample so that the torch spot size would be approximately 10 $15 \mathrm{~mm}$. This, along with constant pressures and flow rates, allowed for the relative performance of the panels to be compared. The water temperature was not controlled, and boiling was allowed but not monitored. Thermocouples were attached to the heated side of the panel to measure the surface temperature, and movies were taken during testing, allowing frame-by-frame inspection to accurately read the measured temperature at the rupture of the panel.

For inspection, samples were mounted and polished using standard metallographic preparation techniques. An etching solution of $33 \% \mathrm{CH}_{3} \mathrm{COOH}, 33 \% \mathrm{H}_{2} \mathrm{O}, 33 \% \mathrm{HNO}_{3}$, and $1 \% \mathrm{HF}$ was used to reveal the $\gamma+\gamma^{\prime}$ microstructure. In addition, an electrolytic solution of $11 \% \mathrm{H}_{3} \mathrm{PO}_{4}, 45.5 \% \mathrm{H}_{2} \mathrm{SO}_{4}$, and $43.5 \% \mathrm{HNO}_{3}$ was used to dissolve the $\gamma$ phase, leaving the $\gamma^{\prime}$ phase intact. The electrolytic etch required $7 \mathrm{~V}$ and approximately $0.2 \mathrm{~A} / \mathrm{mm}^{2}$ during the etching process. The microstructure was examined with a scanning electron microscope (SEM). Microstructural evaluation was performed using a Hitachi S-3200N SEM and a Phillips XL30 field emission gun SEM, both equipped with a removable backscatter electron detector. Electron microprobe analysis via wavelength dispersive spectrometry using a CAMECA SX100 was performed to determine elemental concentration profiles across the sample thickness and through the joints.

\section{Results}

SEM images of the $\gamma^{\prime}$ precipitates resulting from the heat treatments are shown in Fig. 5 . The average precipitate size increases from Figs. 5a-5d. All of the aging treatments appeared to produce spherical precipitates. The shortest aging treatment of $13 \mathrm{~min}$ at $1075^{\circ} \mathrm{C}$ resulted in precipitates approximately $90 \mathrm{~nm}$ in diameter, while the longest treatment of $19 \mathrm{~min}$ had precipitate sizes of approximately $400 \mathrm{~nm}$. The $15 \mathrm{~min}$ aging treatment at $1075^{\circ} \mathrm{C}$ appeared to result in the precipitates closest in size to the goal of $110 \mathrm{~nm}$. The smaller precipitates from the second aging treatment are visible, especially in Fig. 5d. The sample in Fig. $5 \mathrm{~d}$ had a $5 \mathrm{~min}$ aging treatment at $980^{\circ} \mathrm{C}$. The other samples had between 2 and 3 min aging treatments, which resulted in precipitates between approximately 20 and $35 \mathrm{~nm}$.

The single sample tensile tests were performed at room temperature to measure properties and select aging treatments that result in the largest increase in yield strength, for subsequent application to the panels. Table $\underline{3}$ contains the measured yield strength, ultimate tensile strength, and strain at fracture for as-received and strengthened samples. Based on these tests, the improvement in yield strength varied from approximately 240 to $340 \%$, depending on
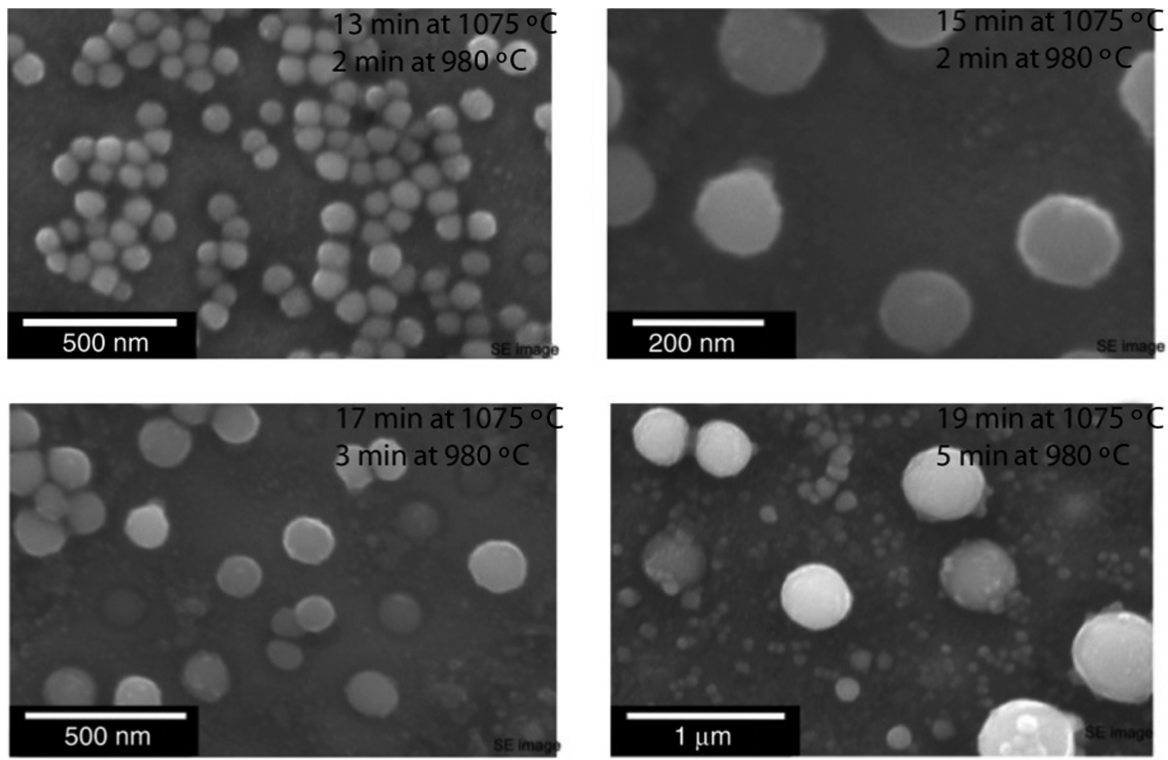

Fig. 5 SEM images of the $\gamma^{\prime}$ precipitates in altered X-750 alloy. 
Table 3 Tensile properties measured and calculated from single tensile tests for as-received $X-750$ alloy and altered $X-750$ alloy with $4.6 \mathrm{wt} \%$ aluminum with varying two-stage aging treatments

\begin{tabular}{cccc}
\hline \hline Sample & $\begin{array}{c}\text { Yield strength, } \\
\mathrm{MPa}\end{array}$ & $\begin{array}{c}\text { Ultimate tensile } \\
\text { strength, MPa }\end{array}$ & $\begin{array}{c}\text { Strain at } \\
\text { fracture, \% }\end{array}$ \\
\hline $\begin{array}{c}\text { As-received } \\
13 \mathrm{~min} \text { at } 1075^{\circ} \mathrm{C}\end{array}$ & 260 & 745 & 28.5 \\
$2 \mathrm{~min}$ at $980^{\circ} \mathrm{C}$ & 887 & 918 & 1.2 \\
$15 \mathrm{~min}$ at $1075^{\circ} \mathrm{C}$ & 879 & 941 & 2.7 \\
$2 \mathrm{~min}$ at $980^{\circ} \mathrm{C}$ & & & \\
$17 \mathrm{~min}$ at $1075^{\circ} \mathrm{C}$ & 724 & 740 & 0.7 \\
$3 \mathrm{~min}$ at $980^{\circ} \mathrm{C}$ & & 705 & 1.8 \\
$19 \mathrm{~min}$ at $1075^{\circ} \mathrm{C}$ & 630 & & \\
$5 \mathrm{~min}$ at $980^{\circ} \mathrm{C}$ & & & \\
\hline \hline
\end{tabular}

the heat treatment, while the strain at fracture had been reduced by at least an order of magnitude. The 13 min aging treatment had the highest yield strength, while the 15 min aging treatment had the highest tensile strength. Considering these results, an aging treatment of $14 \mathrm{~min}$ at $1075^{\circ} \mathrm{C}$ and $2.5 \mathrm{~min}$ at $980^{\circ} \mathrm{C}$ after solutioning for the strengthened panels was chosen to achieve the desired microstructure corresponding to the largest increase in yield and tensile strengths.

To determine the measured temperature at rupture of the asfabricated and strengthened panels, still frames of the movies were examined. The temperature measurement just before failure for the as-fabricated panel was $377^{\circ} \mathrm{C}$, while the strengthened panel failed at a temperature measurement of $855^{\circ} \mathrm{C}$. Although effort was made to align the hottest spot of the torch with the thermocouple, there was a slight offset from the position of the thermocouple. As a result, failure did not occur directly at the thermocouple. However, both panels failed at the same location at similar distances from the thermocouple (Fig. 6). The surface of the as-fabricated panel near the failure location experienced significant outward bowing around the periphery of the failure location, indicating deformation under the action of the internal fluid pressure occurred (Fig. 6). The surface of the VPS strengthened panel in the vicinity of the failure remained relatively flat. After testing, samples and fixtures were inspected to eliminate aberrations in the flow path as causes for the variation in thermal performance. Although slight variations in torch alignment may have contributed to differences in the measured failure temperatures, the following sections present microstructural evidence that corroborates a difference in thermal performance on the order of that recorded by the thermocouples.

To further validate the local temperatures during testing and understand any microstructural changes that occurred, various areas of the strengthened panel were sectioned and the microstructure imaged after failure. Since the volume fraction and degree of coarsening of the strengthening precipitates is highly sensitive to temperature, the precipitates can be used as local indicators of temperature. The panel sections analyzed for precipitate structure included the failure point directly under the thermocouple, in the center of the face sheet, and at a cool section of the panel. The micrographs are shown in Fig. 7 with a schematic showing a portion of the panel. The microstructure near the failure location was substantially altered by the torch heating and consisted of a very low volume fraction of coarse $\gamma^{\prime}$ (Fig. 7a). Microstructures from a cold section of the panel were used to indicate the initial conditions (Fig. 7d). The volume fraction of $\gamma^{\prime}$ just below the thermocouple, at about 40 vol \% (Fig. 7b), remained unchanged, although there was significant coarsening compared with the initial microstructure (Fig. 7d). Together with equilibrium precipitate volume fraction calculations (Fig. 8), the reduced coarsening in the center of the face sheet below the thermocouple (Fig. 7c) compared with directly below the thermocouple (Fig. 7b) suggests that there was a temperature gradient on the order of several $100^{\circ} \mathrm{C}$ across the thickness of the face sheet.

Comparing the calculated equilibrium volume fraction of $\gamma^{\prime}$ in the strengthened panel as a function of temperature (calculated with Pandat ${ }^{\mathrm{TM}}$ ) for the altered X-750 alloy (Fig. 8 ), with the images of the microstructure taken near the failure, it is estimated that the local temperature at which the strengthened panel failed was about $1100^{\circ} \mathrm{C}$. This would mean that the thermocouple that measured $855^{\circ} \mathrm{C}$ at failure was approximately $245^{\circ} \mathrm{C}$ lower than the actual failure temperature. With the similarity of the failure location relative to the thermocouple for the as-fabricated and strengthened panels, it is possible to infer that the actual temperature that the as-fabricated panel experienced at failure was approximately $245 \mathrm{deg}$ higher than the measured temperature of $377^{\circ} \mathrm{C}$, resulting in a temperature at failure of $622^{\circ} \mathrm{C}$.

\section{Discussion}

The overall objective of this study was to establish an approach to strengthen thin-walled thermostructural panels after fabrication into their desired geometrical state. This is necessary if a nickel-based material is to be competitive from a weight and strength standpoint for the combustor of a scramjet engine. Such structures (Fig. 1) could be fabricated from sheet materials via standard sheet forming and/or brazing and welding operations. These processing paths generally require soft sheet materials to avoid damage accumulation during fabrication. In this study, we have demonstrated a straightforward vapor phase approach to strengthening a nickel-base material. Additionally, it is expected that this approach could be expanded to a number of other metallic systems, with consideration of system thermodynamics and precipitation processes.

For the VPS X-750 Ni-base materials examined in this study, the properties of the final sheet material vary with heat treatment times, as reported in Table 3 . As the heat treatment time increases, the room temperature yield strength decreases. Although the 13 and $15 \mathrm{~min}$ aging treatments showed similar yield and ultimate tensile strength, the 17 and 19 min heat treatments had considerable reductions in strength, indicating the microstructure was overaged. The aging treatments that were required to achieve the desired microstructure are not commercially optimal as they are relatively short (14 $\mathrm{min}$ at $1075^{\circ} \mathrm{C}$ and $2.5 \mathrm{~min}$ at $980^{\circ} \mathrm{C}$ ). Although these short aging times are not ideal, a relatively high temperature for the final aging treatment is necessary to make the microstructure more stable at a maximum use temperature of approximately $900^{\circ} \mathrm{C}$. Sheet material compositions designed specifically for this VPS approach would likely permit more optimal heat treatment cycles to be developed.

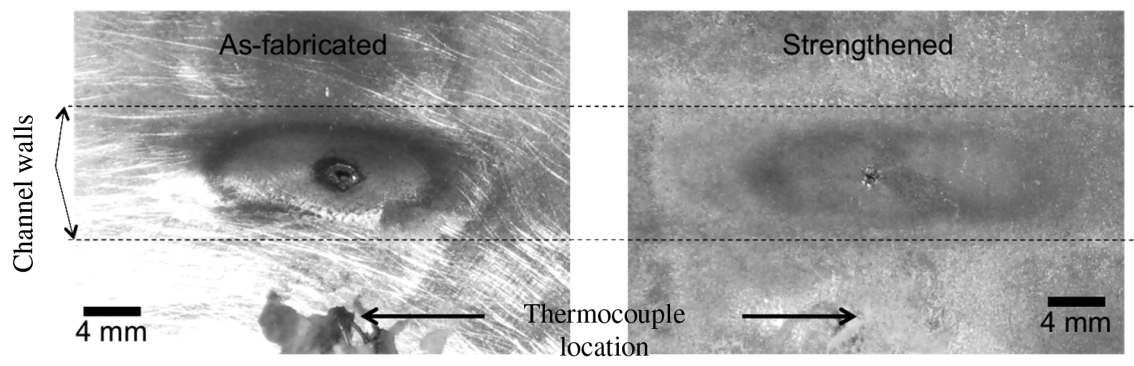

Fig. 6 Image of the as-fabricated and strengthened panels after failure, indicating the relationship between failure location and thermocouple placement. 


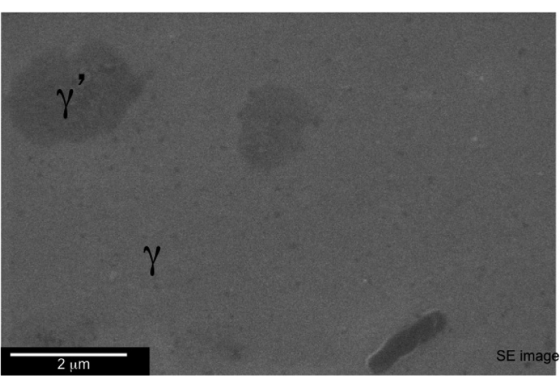

a)

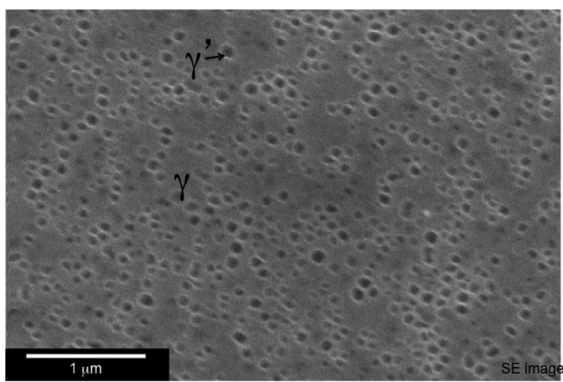

c)

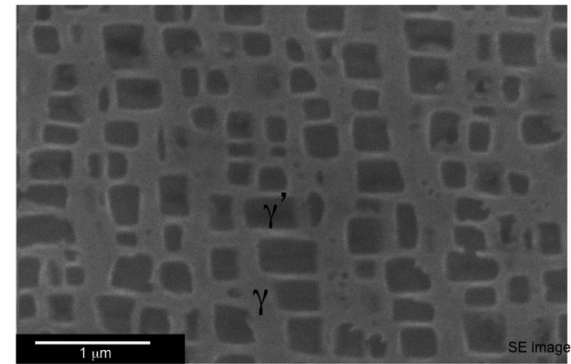

b)

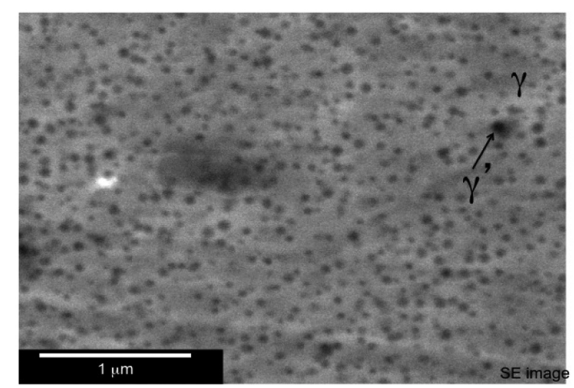

d)

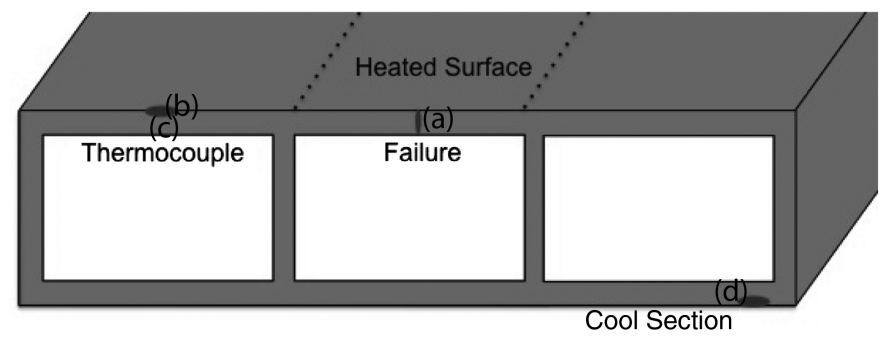

Fig. 7 SEM images of etched material in the strengthened panel after failure at various locations.

As shown in Fig. 7, the microstructure was examined at various locations along the strengthened panel after failure: Fig. 7a corresponds to near the failure, Fig. $7 \mathrm{~b}$ is directly under the thermocouple, Fig. $7 \mathrm{c}$ is from the center of the face sheet under the thermocouple, and Fig. $7 \mathrm{~d}$ is taken from a cool section of the panel. The microstructure at the failure point showed a reduced volume fraction of $\gamma^{\prime}$, which indicates that the temperature at failure was high enough to re-solution most of the $\gamma^{\prime}$ phase into the matrix. As the volume fraction of $\gamma^{\prime}$ is reduced, which occurs above a maximum use

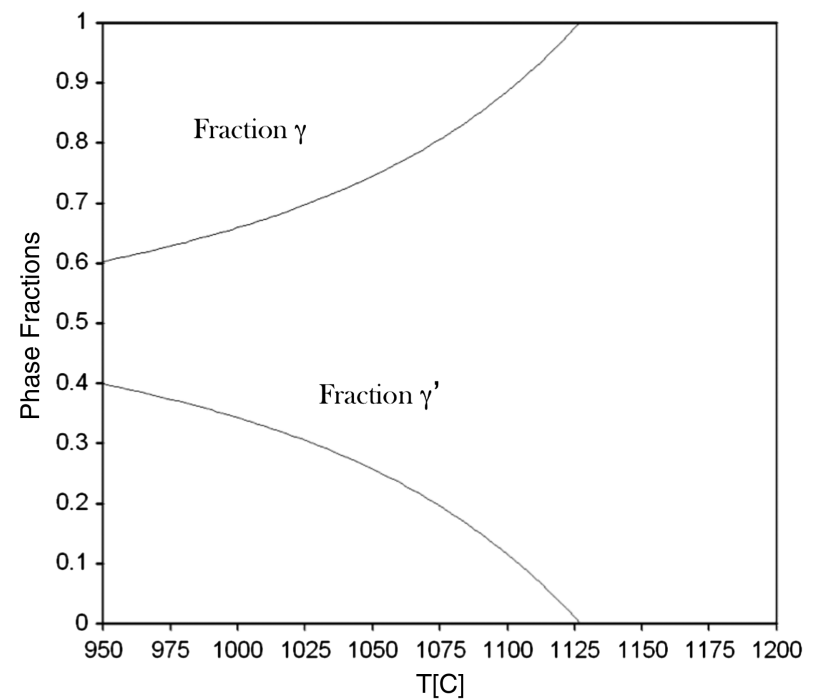

Fig. 8 Volume fraction of phases in equilibrium for an altered X-750 alloy containing $4.6 \mathrm{wt} \%$ aluminum calculated with Pandat ${ }^{\mathrm{TM}}$ software. temperature $T^{*}$, the yield strength of the alloy is reduced. This is why most precipitation-strengthened nickel-based superalloys exhibit the decay in yield stress at higher temperatures, as shown schematically for the as-received and strengthened X-750 alloys in Fig. 9, with a sharp decline in strength above $T^{*}$. Thus, the strengthened panel failed because the panel locally experienced temperatures above the maximum use temperature.

Although this study focused on using X-750 as the starting base alloy, it should be noted that this approach could be applied to a variety of nickel-based alloys in thin sheet form. The feasibility of the strengthening process has been previously demonstrated using a range of commercially available wrought nickel-based alloys, including alloys 214, 625, and 693 [13]. It is necessary to consider

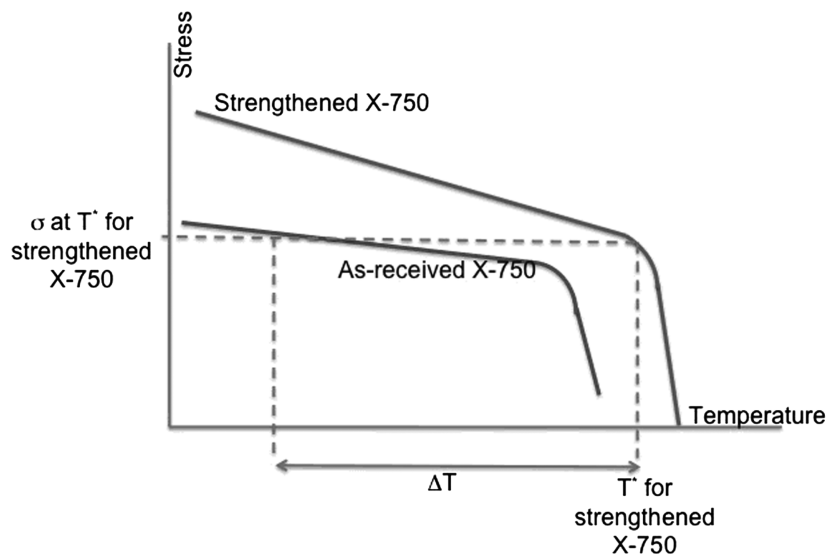

Fig. 9 Schematic of yield strength as a function of temperature for the VPS and as-received X-750 alloys. 
the effects that alloying elements will have on the phases that will be stable after homogenization. For example, the combination of chromium and molybdenum in alloy 625 stabilizes a brittle sigma phase as the aluminum concentration is increased, so this particular alloy is not ideal for the present approach. Using a thermodynamic model such as the Pandat ${ }^{\mathrm{TM}}$ model, the aluminum enrichment can be assessed and tuned to levels that provide maximum strengthening. In this manner, new multicomponent sheet compositions that would have a more favorable microstructural evolution path could be designed.

\section{Conclusions}

1) The VPS process is effective for increasing the strength and temperature capability of a thin-walled component initially fabricated from a wrought nickel-based alloy allowing a metallic thermostructural panel to be a viable material option for the combustor of a scramjet engine.

2) Tensile tests showed an improvement in room temperature yield strength of up to $340 \%$ with the new VPS process.

3) The range of aging treatments allowed for determination of appropriate aging treatments to maximize yield strength for the altered X-750 alloy.

4) The strengthening process was used to achieve a rectangularchanneled thermostructural panel with 0.4-mm-thick face-sheet and web thicknesses and the microstructure that showed the largest improvement in yield strength.

5) Both as-fabricated and strengthened panels were actively cooled with water and subjected to high heat flux torch testing. The VPS panel showed improved temperature capability, surviving to a temperature $478^{\circ} \mathrm{C}$ higher than the X-750 panel without enhanced strengthening.

\section{Acknowledgments}

The support of the U.S. Office of Naval Research (grant N0001405-1-0439) is gratefully acknowledged. The authors also appreciate the assistance of Chris Torbet for helpful discussions and assistance with experimental procedures.

\section{References}

[1] Wicks, N., and Hutchinson, J. W., "Optimal Truss Plates," International Journal of Solids and Structures, Vol. 38, Nos. 30-31, 2001, pp. 51655183. doi:10.1016/S0020-7683(00)00315-2

[2] Evans, A. G., Hutchinson, J. W., Fleck, N. A., Ashby, M. F., and Wadley, H. N. G., "The Topological Design of Multifunctional Cellular Metals," Progress in Materials Science, Vol. 46, Nos. 3-4, 2001, pp. 309-327. doi:10.1016/S0079-6425(00)00016-5

[3] Valdevit, L., Hutchinson, J. W., and Evans, A. G., "Structurally Optimized Sandwich Panels with Prismatic Cores," International Journal of Solids and Structures, Vol. 41, Nos. 18-19, 2004, pp. 51055124 .

doi:10.1016/j.ijsolstr.2004.04.027

[4] Nathal, M. V., Whittenberger, J. D., Hebsur, M. G., Kantzos, P. T., and Krause, D. L., Superalloys 2004, edited by K. A. Green, T. M. Pollock, H. Harada, T. E. Howson, R. C. Reed, J. J. Schirra, and S. Walston, TMS, Baltimore, MD, 2004, pp. 431-439.

[5] Hyun, S., Karlsson, A. M., Torquato, S., and Evans, A. G., "Simulated Properties of Kagomé and Tetragonal Truss Core Panels," International Journal of Solids and Structures, Vol. 40, No. 25, 2003, pp. 6989-6998.
doi:10.1016/S0020-7683(03)00350-0

[6] Zok, F. W., Rathbun, H. J., Wei, Z., and Evans, A. G., "Design of Metallic Textile Core Sandwich Panels," International Journal of Solids and Structures, Vol. 40, No. 21, 2003, pp. 5707-5722. doi:10.1016/S0020-7683(03)00375-5

[7] Rakow, J. F., and Waas, A. M., "Response of Actively Cooled Metal Foam Sandwich Panels Exposed to Thermal Loading," AIAA Journal, Vol. 45, No. 2, 2007, pp. 329-336. doi: $10.2514 / 1.24813$

[8] Rakow, J. F., and Waas, A. M., "Size Effects in Metal Foam Cores for Sandwich Structures," AIAA Journal, Vol. 42, No. 7, 2004, pp. 13311337. doi: $10.2514 / 1.4839$

[9] Streiff, R., and N'Gandu Muamba, J. M., "Surface Morphology of Diffusion Aluminide Coatings," Thin Solid Films, Vol. 119, No. 3, 1984, pp. 291-300. doi:10.1016/0040-6090(84)90013-0

[10] Tu, D. C., and Seigle, L. L., "Kinetics of Formation and Microstructure of Aluminide Coatings on Ni-Cr alloys," Thin Solid Films, Vol. 95, No. 1, 1982, pp. 47-56. doi:10.1016/0040-6090(82)90581-8

[11] Glicksman, M. E., Diffusion in Solids: Field Theory, Solid-State Principles, and Applications, Wiley, New York, 2000, pp. 31-44, 107126.

[12] Hodge, A. M., and Dunand, D.C., "Synthesis of Nickel-Aluminide Foams by Pack-Aluminization of Nickel Foams," Intermetallics, Vol. 9, No. 7, 2003, p. 6989. doi:10.1016/S0966-9795(01)00047-4

[13] Johnson, S. J., Tryon, B., and Pollock, T. M., "Post-Fabrication Vapor Phase Strengthening of Nickel-Based Sheet Alloys for Thermostructural Panels," Acta Materialia, Vol. 56, No. 17, 2008, pp. 45774584. doi:10.1016/j.actamat.2008.05.013

[14] Johnson, S. J., Adaharapurapu, R. R., and Pollock, T. M., Superalloys 2008, edited by R. C. Reed, K. A. Green, P. Caron, T. P. Gabb, M. G. Fahrmann, E. S. Huron, and S. A. Woodard, TMS, Baltimore, MD, 2008, pp. 271-275.

[15] Vermaak, N., Valdevit, L., and Evans, A. G., "Materials Property Profiles for Actively Cooled Panels: An Illustration for Scramjet Applications," Metallurgical and Materials Transactions A: Physical Metallurgy and Materials Science, Vol. 40A, No. 4, 2009, pp. 877-890. doi:10.1007/s11661-008-9768-y

[16] Kozar, R. W., Suzuki, A., Milligan, W. W., Schirra, J. J., Savage, M. F., and Pollock, T. M., "Strengthening Mechanisms in Polycrystalline Multimodal Nickel-Base Superalloys," Metallurgical and Materials Transactions A: Physical Metallurgy and Materials Science, Vol. 40A, No. 7, 2009, pp. 1588-1603. doi:10.1007/s11661-009-9858-5

[17] Valdevit, L., Vermaak, N., Zok, F. W., and Evans, A. G., "A Materials Selection Protocol for Lightweight Actively Cooled Panels," Journal of Applied Mechanics, Vol. 75, No. 6, 2008, Paper 061022. doi:10.1115/1.2966270

[18] "Haynes X750 Alloy Specifications," Haynes International, Kokomo, IN, 2004.

[19] Das, D. K., Singh, V., and Joshi, S. V., "Evolution of Aluminide Coating Microstructure on Nickel-Base Cast Superalloy CM-247 in a SingleStep High-Activity Aluminizing Process," Metallurgical and Materials Transactions A: Physical Metallurgy and Materials Science, Vol. 29A, No. 8, 1998, pp. 2173-2188. doi:10.1007/s11661-998-0042-0

[20] Mévrel, R., Duret, C., and Pichoir, R., "Pack Cementation Processes," Materials Science and Technology, Vol. 2, No. 3, 2001, pp. 581-589.

A. Palazotto Associate Editor 